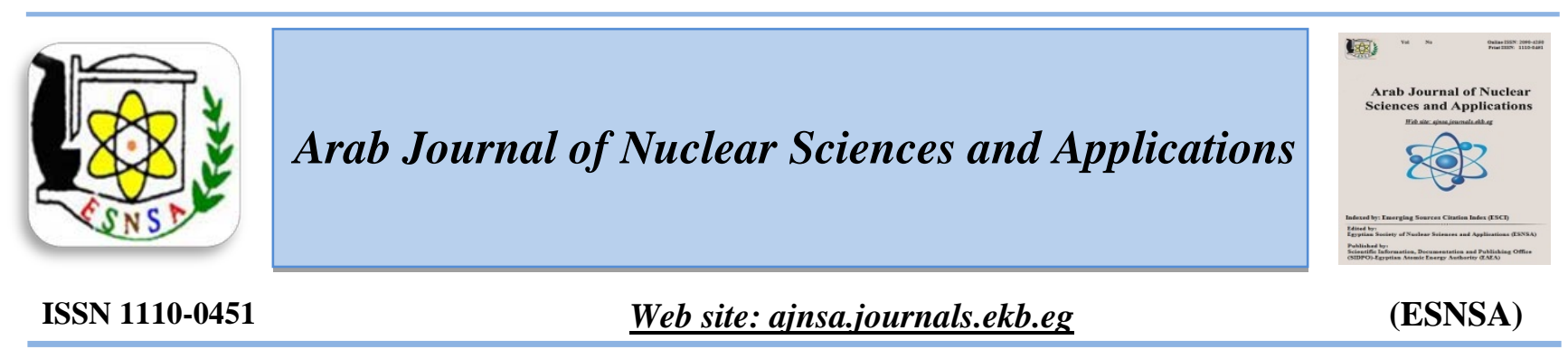

\title{
Recovery of Yttrium and Dysprosium from the Rare Earth Concentrate, Southwestern Sinai, Egypt
}

Mohamed M. Fawzy and Saleh M. Elhady

Nuclear Materials Authority, Cairo, Egypt

Received $20^{\text {th }}$ Sep 2017 Separation of ytrrium and dysprosium from the prepared chloride liquor of HREEs concentrate Accepted $7^{\text {th }}$ Nov 2017 (44.1\% Y, 9.04\% Dy, 5.15\% Er, 4.56\% Gd, 2.31\% Yb, 1.33\% Ho, and 1.23\% Sm) has been studied. The concentrate was obtained by the sulfatizing roasting of xenotime bearing ferruginous sandstone (from southwestern Sinai) followed by precipitation as oxalates then dissolution in $\mathrm{HCl}$. Treatment of the prepared REEs chloride with $\mathrm{Na}_{2} \mathrm{CO}_{3}$ was achieved under suitable conditions by the addition of $\mathrm{H}_{2} \mathrm{O}_{2}$ to the carbonate solution where Dy, Gd, Sm, and Yb are precipitated while $Y$ \& Er left behind in the filtrate. Extraction of $\mathbf{8 7 . 3 \%}$ Dy from the produced precipitate was studied using Cyanex 272. The relevant conditions for extraction and stripping processes have been optimized. After acidification, $Y$ in the filtrate and $\mathrm{Dy}$ in the stripping solution are precipitated as oxalates. Pure products of $\mathrm{Y}_{2} \mathrm{O}_{3}$ and $\mathrm{Dy}_{2} \mathrm{O}_{3}$ have been prepared and subjected to different analyses.

Keywords: Yttrium/Dysprosium/Leaching/ $\mathrm{H}_{2} \mathrm{O}_{2} /$ Extraction/Cyanex272/Xenotime

\section{Introduction}

Much attention has been paid to the uses of rare earth elements (REEs) especially Dy and Y in the manufacture of many functional materials. Dysprosium plays an important role in the manufacturing of laser materials, nuclear reactors, hybrid cars, color television tubes and commercial lighting with vanadium and other elements. Dysprosium's main use is in alloys for neodymium-based magnets. This is because it is resistant to demagnetization at high temperatures [1-5]. Yttrium is used in the manufacturing of ceramics, in fluorescent lighting phosphors, computer displays and automotive fuel consumption sensors because of the highest thermodynamic affinity of yttrium for oxygen of any element. Yttria-stabilized zirconium oxide is used in high temperature applications such as in thermal plasma sprays. Crystals of the yttriumiron-garnet (YIG) variety are essential to microwave communication equipment [6-9]. Vijayalakshmi (2001), described a process for the recovery of rare earths from xenotime concentrate by digestion with sulfuric acid. A low grade xenotime concentrate $\left(27 \% \mathrm{Y}_{2} \mathrm{O}_{3}\right.$ and $15.6 \%$ heavy rare earth) and a high grade xenotime $\left(41.8 \% \mathrm{Y}_{2} \mathrm{O}_{3}\right.$ and $20.55 \%$ heavy rare earths) are produced in India. Both types of grade have been tested and $98 \%$ of metal content has been solublized in sulfuric acid, while the heavy rare earths (HREEs) have been enriched in the filtrate. Other impurities such as iron, uranium, sulfate and phosphate have been effectively removed by precipitation of rare earths with oxalic acid. In this regard the recovery of 99\% of HREEs along with Y was achieved [10].

Separation of individual lanthanides from each other is very difficult due to their chemical similarity. Yttrium and dysprosium is separated via

Corresponding author: mfawzynma@yahoo.com

DOI: 10.21608/ajnsa.2018.6508

CScientific Information, Documentation and Publishing Office (SIDPO)-EAEA 
solvent extraction technique from different acid media using different solvents such as Cyanex 923, bis (2, 4, 4-trimethylpentyl) dithiophosphinic acid, sec-octylphenoxy acetic acid [CA12] synergtic with bis (2, 4-4-trimethylpentyl) phosphinic acid [Cyanex 272], and trialkyl phosphine oxide (TPO) [11-15]. Mohammadi et al. (2015) studied the separation of Dy, Nd, and Y by solvent extraction using D2EHPA and EHEHPA. The results showed that a mixture of D2EHPA and EHEHPA provide a better separation of Y (III) from Dy(III) when the total extractant concentration is 0.06 and 0.09 $\mathrm{mol} / \mathrm{L}$ respectively, while the separation is better using pure EHEHPA alone at higher extractant concentration ( $0.15 \mathrm{~mol} / \mathrm{L})$ [16].

Vasconcellos et al. (2006), studied the solubility of rare earths in $\left(\mathrm{NH}_{4}\right)_{2} \mathrm{CO}_{3}$. The used concentrate contains (\%) $2.4 \mathrm{Y}_{2} \mathrm{O}_{3}, 0.6 \mathrm{Dy}_{2} \mathrm{O}_{3}, 2.7 \mathrm{Gd}_{2} \mathrm{O}_{3}, 2.5$ $\mathrm{CeO}_{2}, 33.2 \mathrm{Nd}_{2} \mathrm{O}_{3}, 40.3 \mathrm{La}_{2} \mathrm{O}_{3}, 4.1 \mathrm{Sm}_{2} \mathrm{O}_{3}$, and 7.5 $\operatorname{Pr}_{6} \mathrm{O}_{11}$. The ability of carbonate for dissolution of rare earths and the easy separation of yttrium was achieved using the precipitation of the peroxide from complex yttrium carbonate. Yttrium was recovered from the carbonate solution as the oxalate and finally as oxide. The final product contains $81 \% \mathrm{Y}_{2} \mathrm{O}_{3}$ [17].

The present work is oriented to study the recovery of $\mathrm{Y}$ and Dy from rare earth concentrate prepared by chemical processing of xenotime bearing ferruginous sandstone, southwestern Sinai. Treatment and precipitation of the REEs chloride (prepared from the concentrate) with $\mathrm{Na}_{2} \mathrm{CO}_{3}$ and $\mathrm{H}_{2} \mathrm{O}_{2}$ respectively were investigated. Yttrium was left behind in the filtrate while the other REEs were precipitated. Separation of Dy has been studied via solvent extraction technique using Cyanex 272 modified in kerosene. Yttrium and dysprosium were precipitated by addition of oxalic acid from their corresponding solutions after being acidified with $\mathrm{HCl}$.

\section{EXPERIMENTAL}

\section{Materials preparation}

The working rare earth concentrate has been prepared from the xenotime bearing ferruginous sandstone of Wadi El Sahu, southwestern Sinai. The latter is chemically processed with concentrated $\mathrm{H}_{2} \mathrm{SO}_{4}$ (in $1 / 1.5 \mathrm{~S} / \mathrm{L}$ ratio at $250^{\circ} \mathrm{C}$ for $2 \mathrm{~h})$ where about $>90 \%$ of the REEs are solubilized. The REEs sulfate was precipitated as oxalates then calcined at $850^{\circ} \mathrm{C}$ [18]. A known weight of the obtained rare earth oxides is dissolved by a calculated volume of $\mathrm{HCl}$ in the beaker with continuous heating followed by addition of de-ionized water to obtain rare earth chloride solution. Bis(2,4-4-trimethylpentyl) phosphinic acid [Cyanex 272] was provided by Loba Chemie PVT. LTD, while kerosene, methanol, $\mathrm{HCl}$ and $\mathrm{Na}_{2} \mathrm{CO}_{3}$ were provided by ElNasr Chemicals Company, Egypt.

\section{Separation investigations}

Several experiments were performed by the reaction of a known volume of rare earth chloride solution with an equal volume of $\mathrm{Na}_{2} \mathrm{CO}_{3}$ solution at room temperature under different conditions. The precipitation of heavy rare earths (except Y) from carbonate solution was carried out by the addition of different volumes of $\mathrm{H}_{2} \mathrm{O}_{2}$. Yttrium was left behind in the filtrate (which was undergone precipitation using oxalic acid), while the peroxy precipitate was acidified with $\mathrm{HCl}$ and reacted with modified Cyanex 272 in kerosene under suitable conditions. The stripping of Dy from Cyanex 272 has been performed using $\mathrm{HCl}$ solution under desired conditions. However the recovery of Dy was also carried out by precipitation with oxalic acid.

\section{Material analysis}

The rare earth contents in the solid concentrate are analyzed (Fig.(1)) using scanning electron microscopy (SEM), JSM-84OA, JEOL, Tokyo, Japan, with the possibility of enlargement by 180.000 times and the resolution of $10 \mathrm{~nm}$. For determining the concentration of individual heavy rare earth elements, ICP-MS spectrometry model Philips PV 8490, China was used [19]. The capability of (ICP-MS) for simultaneous multielement determination makes it very attractive for the analysis of geological and chemical materials. Morphologically, the solid REEs concentrate have a yellowish white color and relatively soft grains [18]. Chemically, the obtained concentrate mainly contains \% of $44.08 \mathrm{Y}, 9.04 \mathrm{Dy}, 5.15 \mathrm{Er}, 4.56 \mathrm{Gd}$, $2.31 \mathrm{Yb}, 1.33 \mathrm{Ho}, 1.23 \mathrm{Sm}$, and minor amounts of some impurities.

Analysis of heavy rare earth elements for proceeding the extraction step was carried out, the concentration of prepared sample was measured (Co) before and after each experimental (treatment 
Recovery of Yttrium and Dysprosium.....

and extraction) step. The experimental (E) \% can be calculated as follow:

Experimental efficiency (E) \%

$$
=\left[\left(\mathrm{C}_{\mathrm{o}}-\mathrm{C}_{\mathrm{f}}\right) / \mathrm{Co}\right] \times 100
$$

Where, $\mathrm{C}_{\mathrm{o}}$ is the concentration of the initial HREE concentration sample while $C_{f}$ is the final concentration after treatment process.

\section{Results and Discussion}

Preparation procedure

The working rare earth concentrate of $40 \mathrm{~g}$ (produced via the chemical processing of xenotime bearing ferruginous sandstone as mentioned above) is digested with $50 \mathrm{ml}$ concentrated $\mathrm{HCl}$ with continuous heating until evaporated to half volume. REEs are completely dissolved followed by addition of distilled water to attain up to 1000 $\mathrm{ml}$. Analysis of the chloride liquor indicate that the concentration of rare earths have attained 19.8, 4.78, 2.74, 2.05, 1.24, 0.14, and $0.08 \mathrm{~g} / \mathrm{l}$ for $\mathrm{Y}$, Dy, Er, Gd, Yb, Ho, and Sm respectively (Table 1).

\section{Sodium carbonate treatment}

The carbonate chemistry is very important for precipitation of the rare earths [17]. Rare earths carbonate system is of utmost importance degree from both the analytical and industrial aspects and solubility efficiency of rare earth elements depends on many factors such as reaction time and $\mathrm{Na}_{2} \mathrm{CO}_{3}$ concentration.

\section{Effect of reaction time}

Series of experiments were performed at room temperature by reaction of $10 \mathrm{ml}$ prepared $\mathrm{RECl} 3$ sample with the same volume of $1 \% \mathrm{Na} 2 \mathrm{CO} 3$ (10 $\mathrm{ml}$ ) under different periods of time ranging from 10 to 30 min. The results have been plotted in Fig. (2). The results show that, at $20 \mathrm{~min}$. the solubility efficiency has reached the values of 63.1, 53.7, 49.2, 48.4, and 37.2\% for Y, Dy, Er, Gd, and Yb respectively, with trace concentration of $\mathrm{Sm}$ and Ho. Further increase in the reaction time (more than $20 \mathrm{~min}$ ) indicates that there was no sensible increase in the solubility efficiency of the rare earth elements.

\section{Effect of $\mathrm{Na}_{2} \mathrm{CO}_{3}$ concentration}

Different concentrations of $\mathrm{Na} 2 \mathrm{CO} 3$ ranging from 1 to $7 \%$ have been studied for $20 \mathrm{~min}$. at room temperature using the equal volume of the prepared HREEs sample and Na2CO3. The results of the solubility efficiency of HREEs have been plotted in Fig. (3).

The results indicate that under the applied experimental conditions, the dissolution of individual rare earth elements in (5\%) $\mathrm{Na}_{2} \mathrm{CO}_{3}$ has increased to become 88.3, 84.2, 64.6, 57.3, and 46.2 for Y, Dy, Er, Gd, and Yb respectively (Fig. (3)). However for concentration more than $5 \%$ of $\mathrm{Na}_{2} \mathrm{CO}_{3}$, the solubility of yttrium \& dysprosium has slightly increased. This indicates that the heavy rare earths solution has saturated with carbonate (17). Therefore, it can be concluded that 5\% $\mathrm{Na}_{2} \mathrm{CO}_{3}$ would be considered as an optimum concentration to reach the maximum dissolution of individual heavy rare earth elements in the carbonate system.

\section{Recovery of yttrium oxide $\left(\mathrm{Y}_{2} \mathrm{O}_{3}\right)$}

Series of precipitation experiments were performed at room temperature, by adding different volumes of $\mathrm{H} 2 \mathrm{O} 2$ ranged from 10 to100 $\mathrm{ml}$ to $50 \mathrm{ml}$ rare earths carbonate solution (containing 17.45 g/l Y, 4.02 g/l Dy, 1.77 g/l Er, $1.17 \mathrm{~g} / \mathrm{l} \mathrm{Gd}$, and $0.57 \mathrm{~g} / \mathrm{l} \mathrm{Yb}$ ) (Table 2).

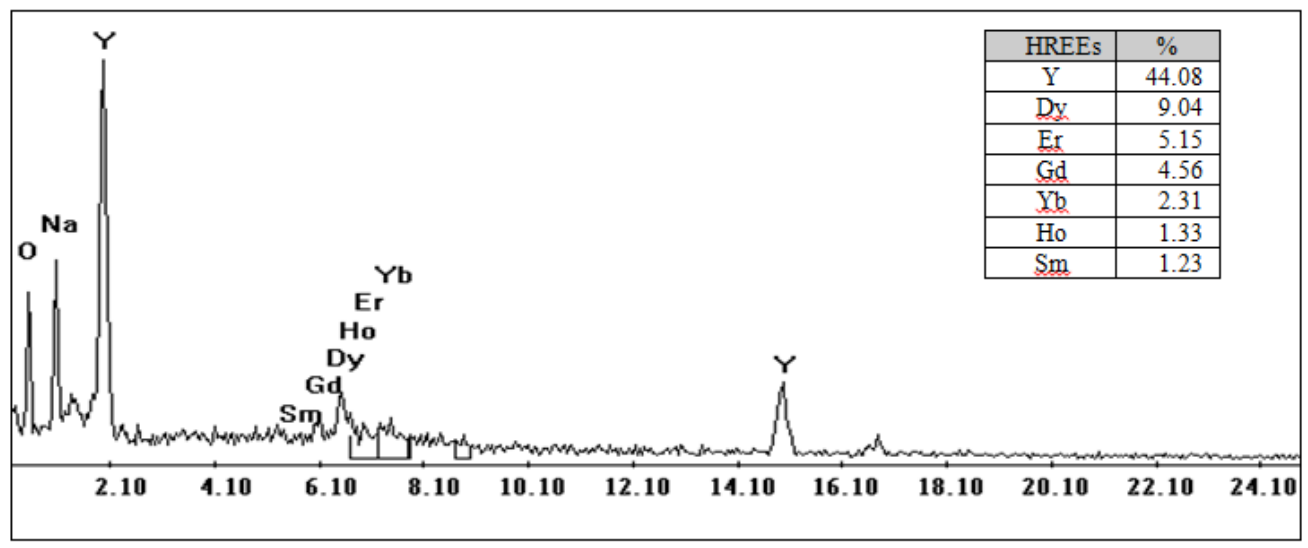

Fig. (1): SEM analysis of HREEs in the xenotime concentrate 
Table (1): Analysis of the REEs chloride liquor

\begin{tabular}{cccccccc}
\hline Elements & Y & Dy & Er & Gd & Yb & Ho & Sm \\
\hline Conc. (g/l) & 19.8 & 4.78 & 2.74 & 2.05 & 1.24 & 0.14 & 0.08 \\
\hline
\end{tabular}

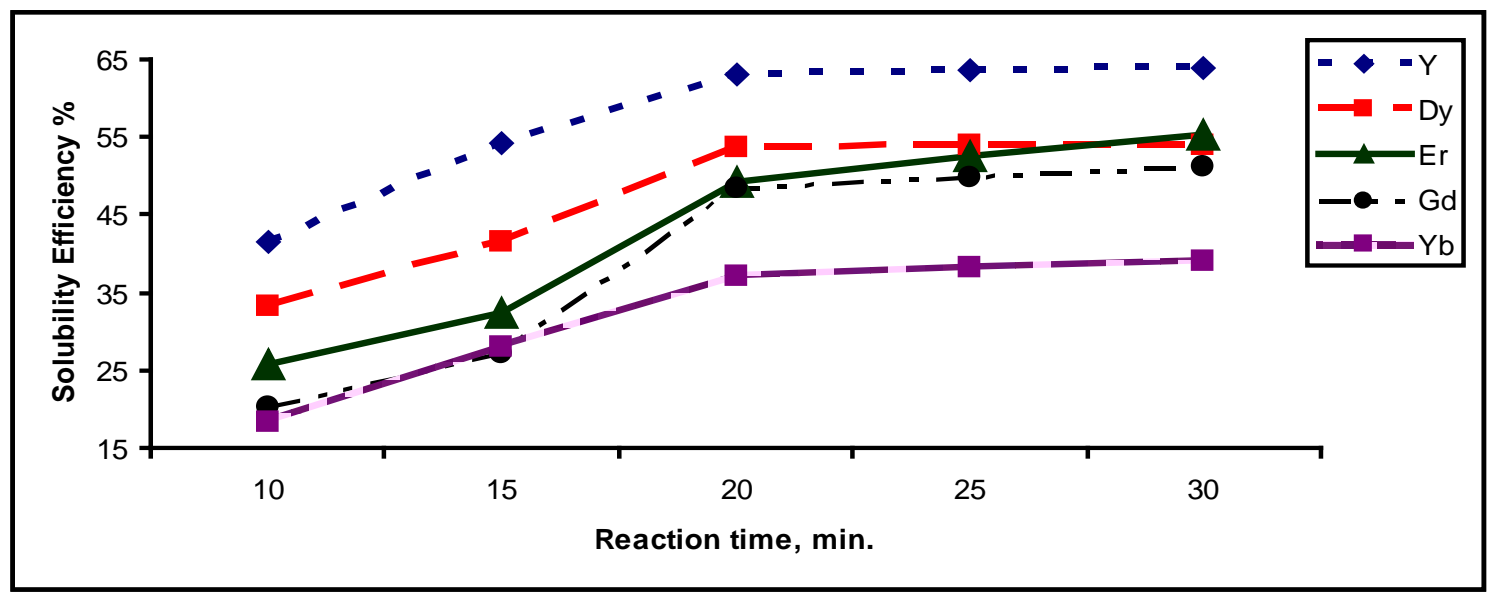

Fig.(2): Effect of reaction time on the solubility of heavy rare earths

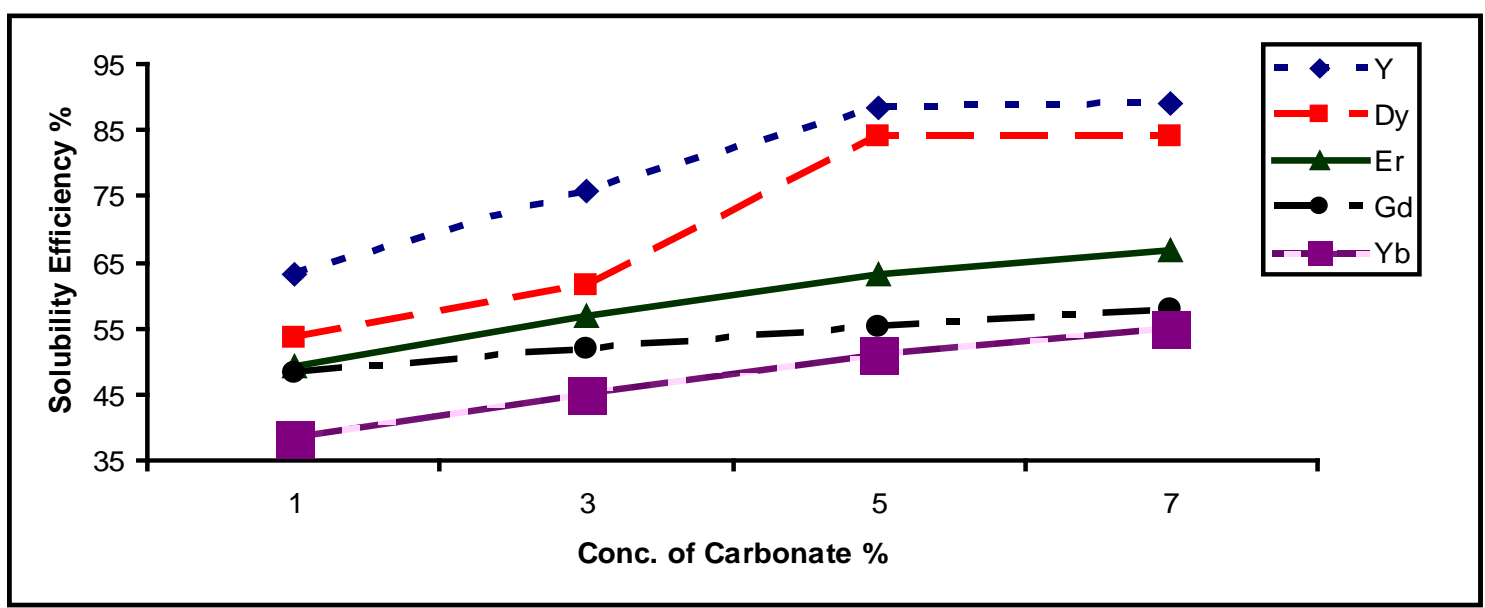

Fig.(3): Effect of carbonate concentration on the dissolution of heavy rare

Table (2): Effect of $\mathrm{H}_{2} \mathrm{O}_{2}$ addition on the precipitation of REEs.

Volume of $\mathrm{H}_{2} \mathrm{O}_{2}$

Precipitation Efficiency \%

\begin{tabular}{cccccc} 
& Y & Dy & Er & Gd & Yb \\
\hline $20 \mathrm{ml}$ & Nil & 45.9 & Nil & 39.7 & 25.4 \\
$40 \mathrm{ml}$ & Nil & 67.3 & Nil & 53.8 & 46.2 \\
$60 \mathrm{ml}$ & Nil & 81.3 & Nil & 69.3 & 56.4 \\
$80 \mathrm{ml}$ & Nil & 97.8 & 5.1 & 83.2 & 67.1 \\
$100 \mathrm{ml}$ & Nil & 98.0 & 5.8 & 83.7 & 67.3 \\
\hline
\end{tabular}


Recovery of Yttrium and Dysprosium.....

From Table 2, it is clear that the precipitation efficiency for Dy, Gd, and $\mathrm{Yb}$ is increased with increasing the added volume of $\mathrm{H} 2 \mathrm{O} 2$ to reach $97.8,83.2$ and $67.1 \%$ respectively at $80 \mathrm{ml}$ $\mathrm{H} 2 \mathrm{O} 2$. On the other hand, $\mathrm{Y}$ is not absolute precipitation while $\mathrm{Er}$ was suspended and completely precipitated after settling for $24 \mathrm{~h}$. The produced peroxycarbonate HREE precipitate contains $96.8 \% \mathrm{Dy}, 73.0 \% \mathrm{Gd}$, and $57.0 \% \mathrm{Yb}$.

Yttrium was recovered from the filtrate after being washed with $20 \mathrm{ml} \mathrm{H} 2 \mathrm{O} 2$ to precipitate the residue of HREEs and acidified with $\mathrm{HCl}$ to $\mathrm{pH} 2$ followed by addition of oxalic acid. The light yellow precipitate oxalate was dried and ignited to oxide (20). The scan electron microscopy (SEM) of obtained oxides contains $91.6 \% \mathrm{Y}_{2} \mathrm{O}_{3} \& 2.7 \% \mathrm{Er}_{2} \mathrm{O}_{3}$ (Fig.4).

\section{Extraction experiments}

In general, liquid-liquid extraction is based on the transfer of a solute substance from one liquid phase to another one according to the solubility. Extraction becomes a very useful tool when choosing a suitable solvent [11-15]. The rare earth solutions were prepared by the dissolution of the peroxycarbonate precipitate of Dy, Gd, and traces of $\mathrm{Yb}$ with $\mathrm{HCl}$. Series of experiments were carried out using Cyanex 272 in kerosene as follow:

\section{Effect of shaking time}

It is well known that the shaking time is one of the predominant factors governing extractability. The extraction of rare earths was conducted for different durations ranging from 5 to $25 \mathrm{~min}$. (Fig.5). The other fixed operating conditions were $1 / 1$ organic/aqueous phase ratio using $0.1 \mathrm{M}$ cyanex concentration at room temperature.

The obtained results show that the extraction efficiency of Dy, Gd and $\mathrm{Yb}$ elements was increased with shaking time to reach 33.1, 11.9 and $3.08 \%$ respectively after $15 \mathrm{~min}$. However, when the contact time exceeded $15 \mathrm{~min}$, the extraction efficiency was constant. The low values of extraction efficiency after 5 min were due to the fact that the feed passed immediately into the solvent without separation. As the contact time is increased, the solvent phase became rich in the feed and therefore, the extraction efficiency of heavy rare earth elements increased. The period of $15 \mathrm{~min}$ is the suitable time which gives the highest values for extraction process of dysprosium. The results for the effect of shaking time were in agreement with the findings of Buchalova et al., (1990) [20] as well as Jorjani and Shahbazi (2016) [15].

\section{Effect of phase modifier}

During the contact of solvent (cyanex 272) with HREEs chloride solution (free from Y), a third phase of an insoluble viscous solution was formed. Several experimental conditions such as aqueous acidity, extracted metal, diluent and extractant structure can affect the formed third phase. This phenomenon is more important for extraction systems containing extractants of amine type and solvents with low polarity and leads to the increase of separation duration simultaneously with the diminution of its efficiency. The formation of the third phase can be avoided by addition of a "phase modifier" to the organic solvent [21]. Generally, an alcohol with an aliphatic chain carbon atom and modifies the polarity of the solvent, promoting the breakage of the stable emulsion and solubilization of its content.

Methanol has been tested under different concentrations ranging from 0.05 to $0.5 \mathrm{M}$ to show the variation in extraction efficiency values using equal organic/aqueous ratio by the addition of $(0.1 \mathrm{M})$ cyanex concentration in kerosene and shaking for15 min. (Fig.6). The results show that, the concentration of $0.3 \mathrm{M}$ methanol gives the highest values of extraction efficiency for dysprosium which corresponds to $68.3 \%$ and an appreciable increase was occurred after this value for Gd \& Yb which equals $28.9 \& 22.3 \%$ respectively. The addition of methanol induced the increase of the extraction efficiency because if its ability to dissolve in the two phase, and the most important influence being recorded for the solvent with lower polarity. Moreover, the volumetric fraction of alcohol controls the number of extractant molecules participating in the interfacial product formation [22]. 


\section{Effect of solvent concentration}

The effect of solvent concentration on rare earth extraction was studied by varying the cyanex 272 concentrations in kerosene from $0.1 \mathrm{M}$ to $1.0 \mathrm{M}$ modified by $0.3 \mathrm{M}$ methanol and dissolved in kerosene (Fig.7). The extraction experiments were carried out using equal (organic/aqueous) ratios under a contact time of 15 min.

From the results, it is noticed that the extraction efficiency for Dy increased with the cyanex 272 concentration from $0.1 \mathrm{M}$ to $0.4 \mathrm{M}$ which reaches $87.3 \%$ at $0.3 \mathrm{M}$ cyanex 272 . However, a slight increase in the extraction efficiency of dysprosium was observed when the concentration of cyanex 272 was increased more than $0.4 \mathrm{M}$. The extraction of Gd \& Yb increased gradually at concentrations higher than $0.4 \mathrm{M}$ cyanex 272 to reach 51.2 \& $38.4 \%$ respectively. So the cyanex 272 concentration of $0.4 \mathrm{M}$ was selected as a suitable concentration for Dy extraction.

The plotted data showed that, the extractant concentration plays a significant factor in the extraction process. Cyanex 272 was chosen as the extractant of heavy rare earths due to both its excellent chemical stability and its physical properties. However, it is limited by its high viscosity and density. A diluent such as kerosene reduces the viscosity and density of the organic phase to improve the phase separation characteristics and high masse transfer (Gupta and Krishnamurthy 1992 2005) [23-24].

\section{Effect of organic/aqueous ratio}

At room temperature, the volumes of modified cyanex $272(0.4 \mathrm{M})$ in kerosene ranging from 50 - $400 \mathrm{ml}$ (which corresponding to 0.5:1 up to 4:1 organic/aqueous phase ratio) were contacted with $100 \mathrm{ml}$ from each rare earths samples for $15 \mathrm{~min}$. The values of extraction efficiency percent of rare earths elements were shown in Fig.(8). The data show that there is an increase in the extraction efficiency of rare earths till ratio $1: 1$, which corresponding to 87.3, 39.1, and 32.5\% for Dy, Gd, and $\mathrm{Yb}$ respectively. After this ratio (for Dy) the effect of organic/aqueous ratio on the extraction process was decreased, i.e. by increasing organic/aqueous ratio, the extraction efficiency decreases gradually. This behavior indicates that the extraction efficiency was affected by the viscosity of the solvent as the low viscosity leads to low pressure drop and good mass transfer [20-21].

\section{Successive extraction steps}

Extraction of heavy rare earths using $0.4 \mathrm{M}$ cyanex 272, modified with $0.3 \mathrm{M}$ methanol, in kerosene was carried out three times using 1:1 (organic/aqueous) phase ratio, at room temperature for $15 \mathrm{~min}$. The results are graphically represented in Fig.(9).

The results indicate that the extraction efficiency \% of Dy, Gd, and Yb increases after the second successive step which becomes $92.7,54.7$, and $42.5 \%$ respectively, while in the third extraction process, the extraction efficiency was increased slightly due to the effect of saturation as well as the capacity of solvent [26]. It is more efficient to perform a two extraction step regime with half volume of solvent rather than total volume.

\section{Stripping investigations}

The stripping investigations were carried out using diluted $\mathrm{HCl}$ to determine the suitable conditions for recovering Dy from the loaded organic solution. The effect of contact time, $\mathrm{HCl}$ concentration, and aqueous/organic phase ratio was studied.

\section{Effect of stripping time}

The effect of stripping time on the recovery of $\mathrm{Dy}, \mathrm{Gd}$, and $\mathrm{Yb}$ from cyanex solution was investigated using $0.05 \mathrm{M} \mathrm{HCl}$ (Fig.10). The process was performed using equal phase ratio (1st step) at room temperature, while the contact time was ranged from 5 to $20 \mathrm{~min}$. The results indicate that the stripping efficiency \% of Dy increases with time increase from 5 to 15 min. (Fig.(10)) and then remains constant till 20 $\mathrm{min}$. This indicates that the process is rapid, i.e. is not a diffusion controlled process [25-26]. The stripping percent of Dy and Gd at $15 \mathrm{~min}$. equals 61.4 and 19.3 respectively, while the \% of $\mathrm{Yb}$ was not detected. 


\section{Effect of HCl concentration}

For the best stripping of Dy uploaded on cyanex 272, the concentration of $\mathrm{HCl}$ was varied from 0.05 to $0.3 \mathrm{M}$ and the process was carried out under room temperature in time equal $15 \mathrm{~min}$. The results were diagrammatically shown in Fig. (11).

The results indicate that, by increasing the $\mathrm{HCl}$ conc. from 0.05 to $0.2 \mathrm{M}$, the stripping efficiency becomes 81.4 and 31.8\% for Dy and Gd respectively. After this concentration, the value of stripping efficiency was slightly increased due to decrease the capacity of carbonate solution as well as the viscosity of organic phase which lead to increase the reversible effect of solvent as well as decrease the mass transfer [22].

\section{Effect of aqueous/organic ratio}

Different phase ratios of $\mathrm{HCl}$ solution and cyanex 272 (loaded with Dy, Gd, and Yb) were studied ranging from 0.5 to 3 at room temperature during $15 \mathrm{~min}$. (Fig. (12) ) to show the maximum efficiency for stripping of HREEs from the organic phase.

The stripping efficiency \% was increased with the value of the aqueous/organic ratio and reached the maximum value at the ratio 2:1 which corresponds to stripping 89.6 and 36.3\% of Dy and Gd respectively (Fig.(12)). Further increase in aqueous/organic ratio was associated with a very slight increase in the stripping percent. Accordingly, aqueous/organic phase ratio of a 2:1 is recommended for stripping of dysprosium from modified cyanex 272 in kerosene when using $0.2 \mathrm{M} \mathrm{HCl}$ at room temperature for $15 \mathrm{~min}$. contact time.

Precipitation of $\mathrm{Dy}_{2} \mathrm{O}_{3}$

In bench-scale work, the mixed lanthanides Dy and Gd were precipitated from the strip liquors by the addition of excess of oxalic acid with stirring for $1 \mathrm{~h}$. The precipitated oxalate was filtered, washed with distilled water and calcined in a muffle furnace at $850^{\circ} \mathrm{C}$ for $2 \mathrm{~h}$ to obtain a dysprosium oxide $\left(\mathrm{Dy}_{2} \mathrm{O}_{3}\right)$ [17]. The rare earth oxide ( $\Sigma$ REO) product, analyzed by ICP-MS apparatus, contains 88.2, and $9.7 \%$ of $\mathrm{Dy}_{2} \mathrm{O}_{3}$ and $\mathrm{Gd}_{2} \mathrm{O}_{3}$ respectively. The scan electron microscopy (SEM) for the REO was shown in Fig. (13). The mixed rare earth oxide was in the form of light brownish powder, analysis of the rare earth oxides in about $0.25 \mathrm{~g}$ of the product gave a $\Sigma$ REO content of $97.9 \%$.

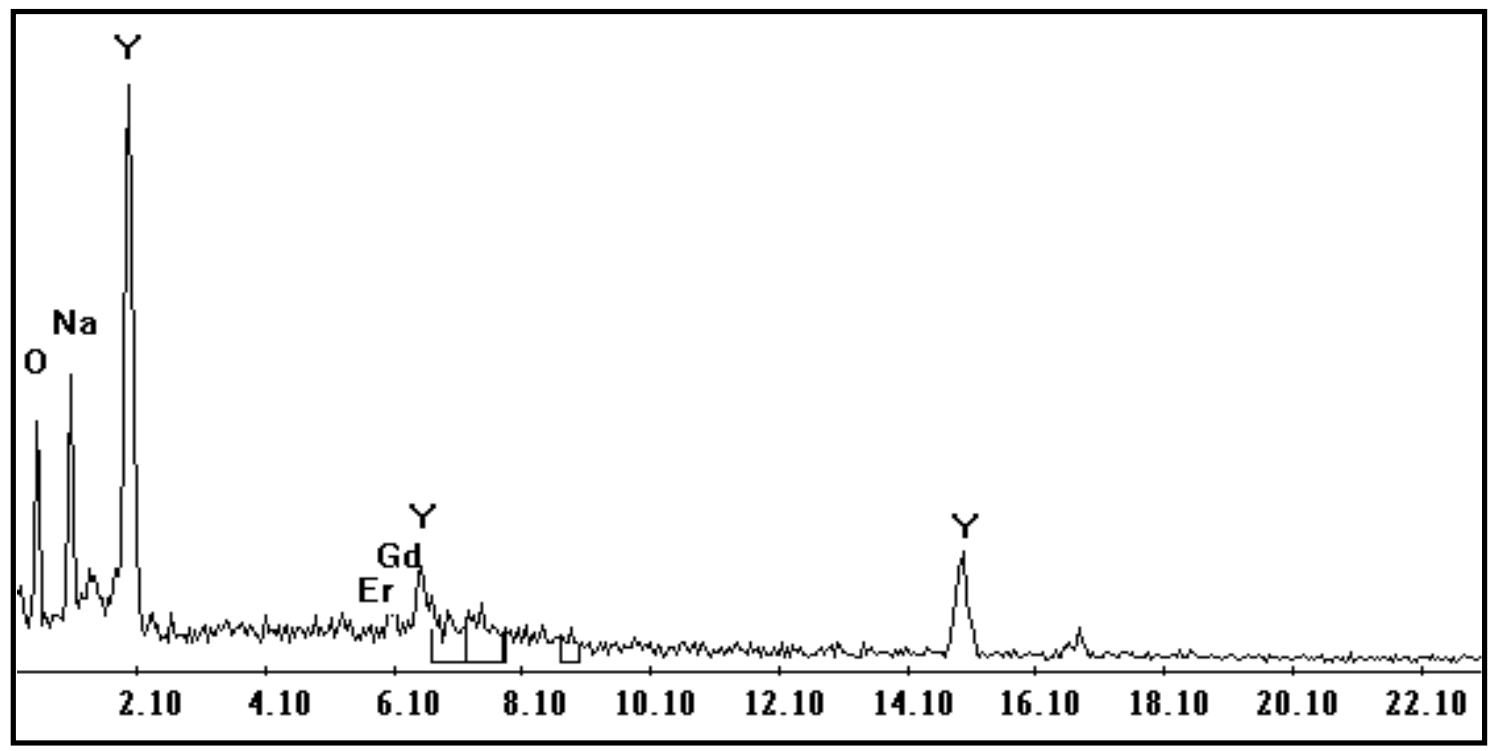

Fig.(4): Scan electron microscopy analysis (SEM) of the yttrium product 


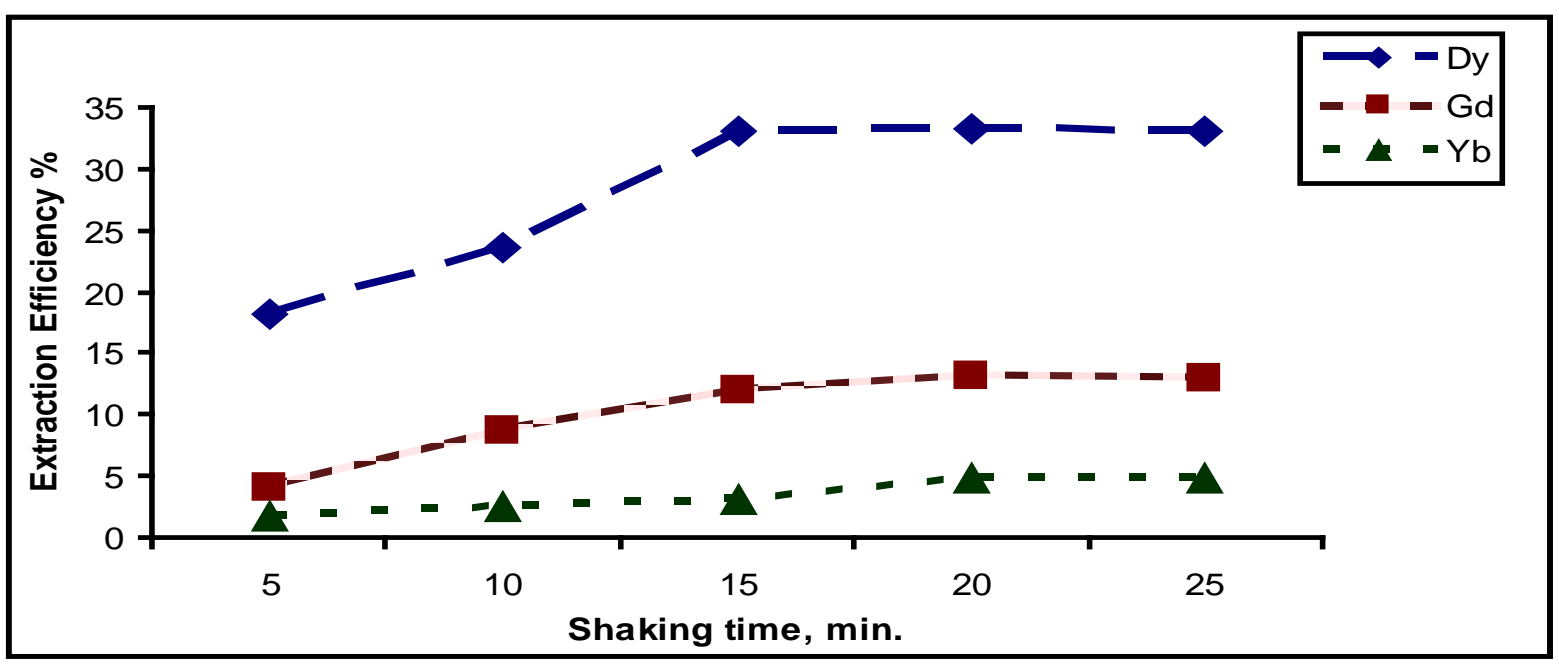

Fig.(5): Effect of shaking time on the extraction of rare earths

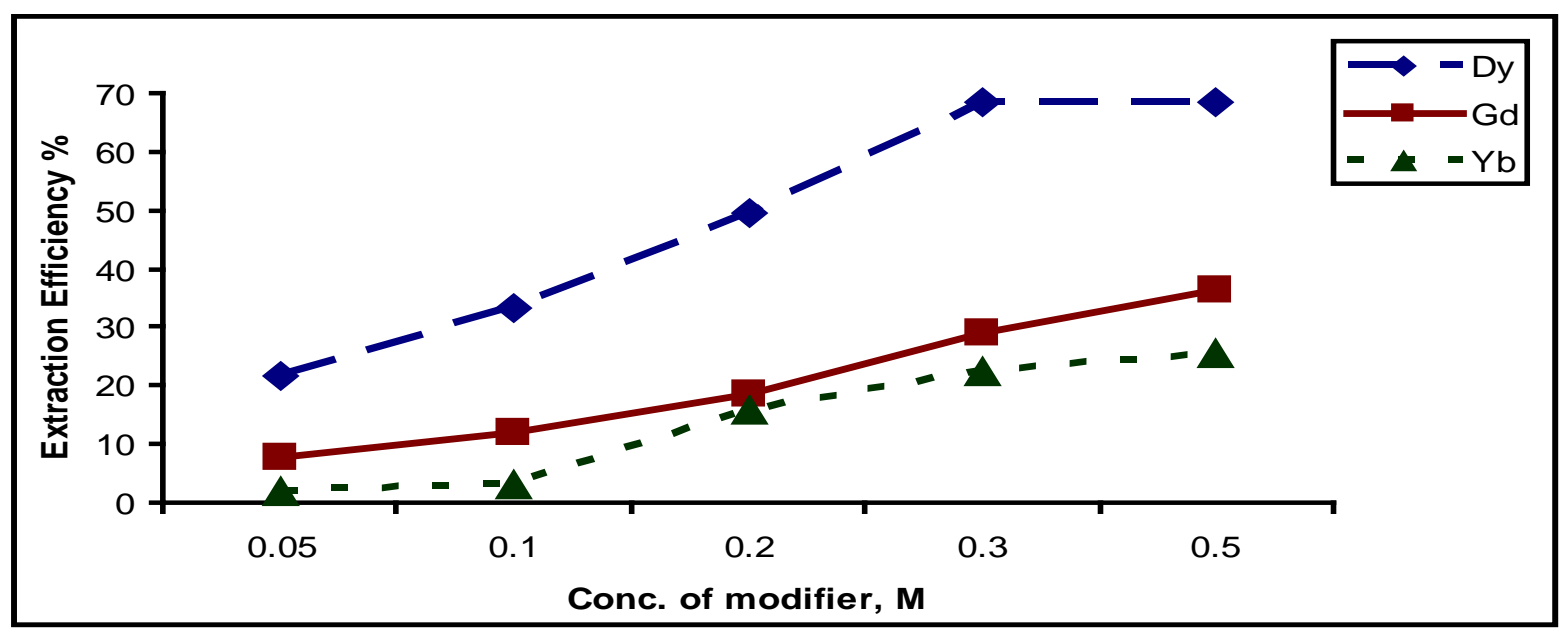

Fig.(6): Effect of modifier addition on the extraction of rare earths

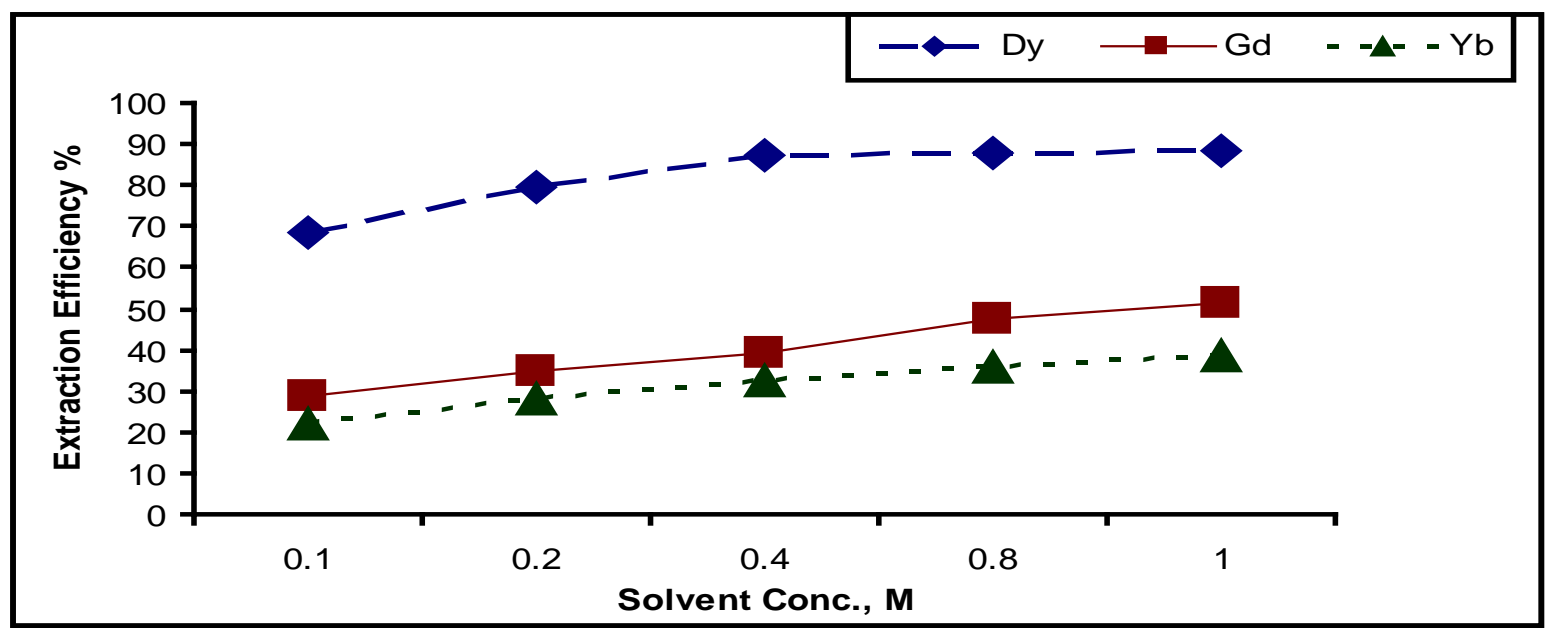

Fig.(7): Effect of Cyanex 272 concentration on the extraction of rare earths

Arab J. Nucl. Sci. \& Applic. Vol. 51, No.2 (2018) 


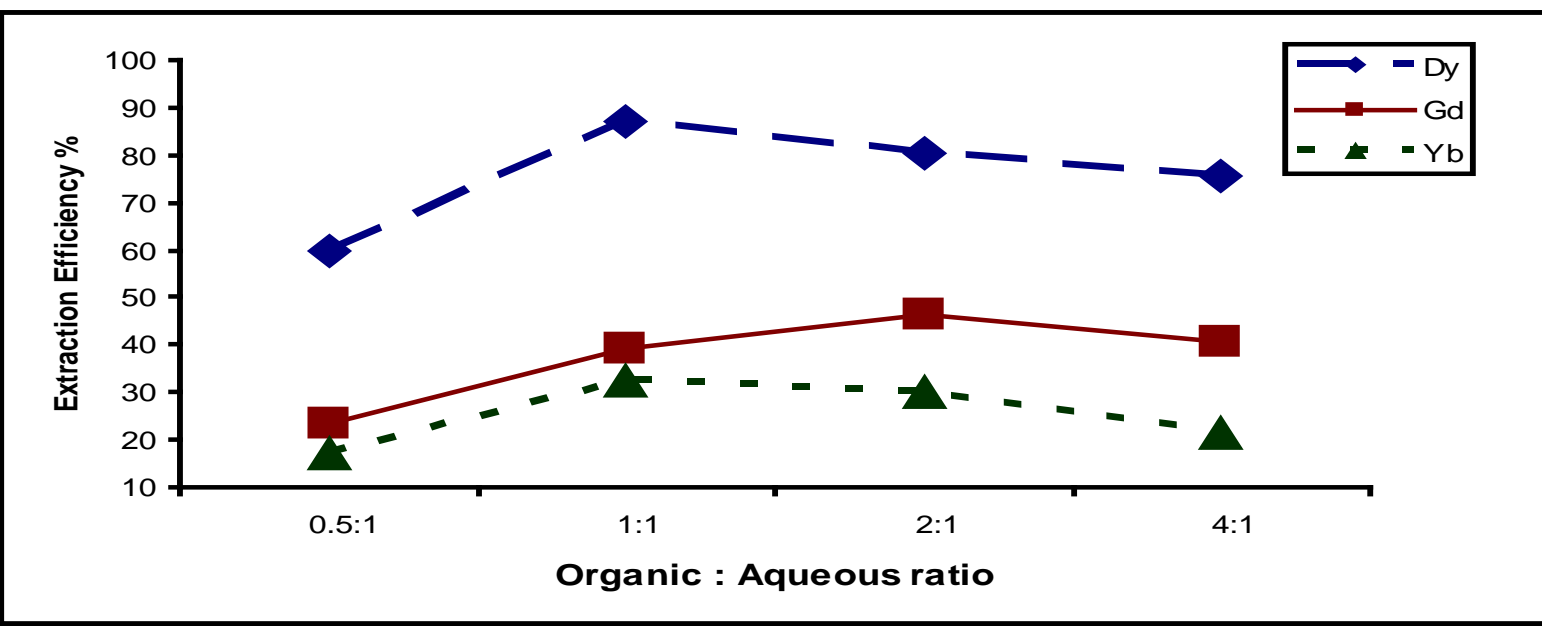

Fig.(8): Effect of organic/aqueous ratio on the extraction of rare earths

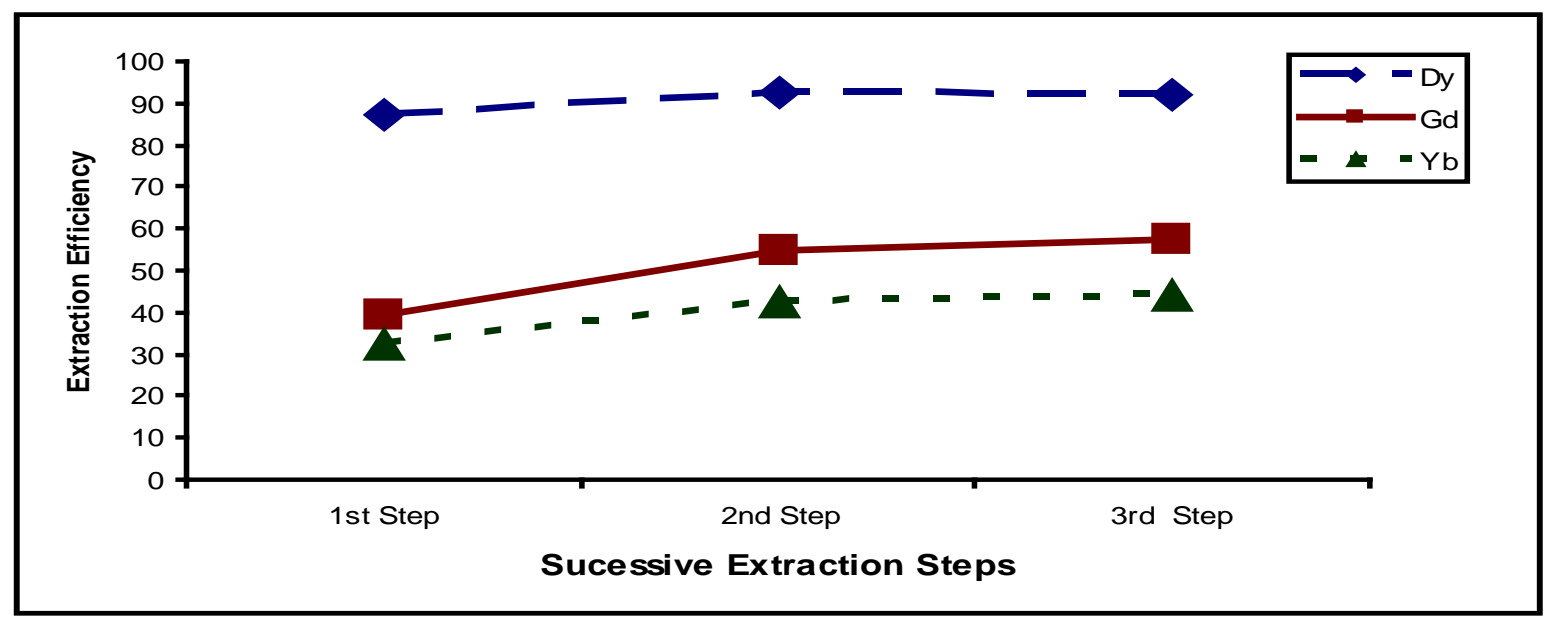

Fig.(9): Effect of successive steps on the extraction of rare earth elements

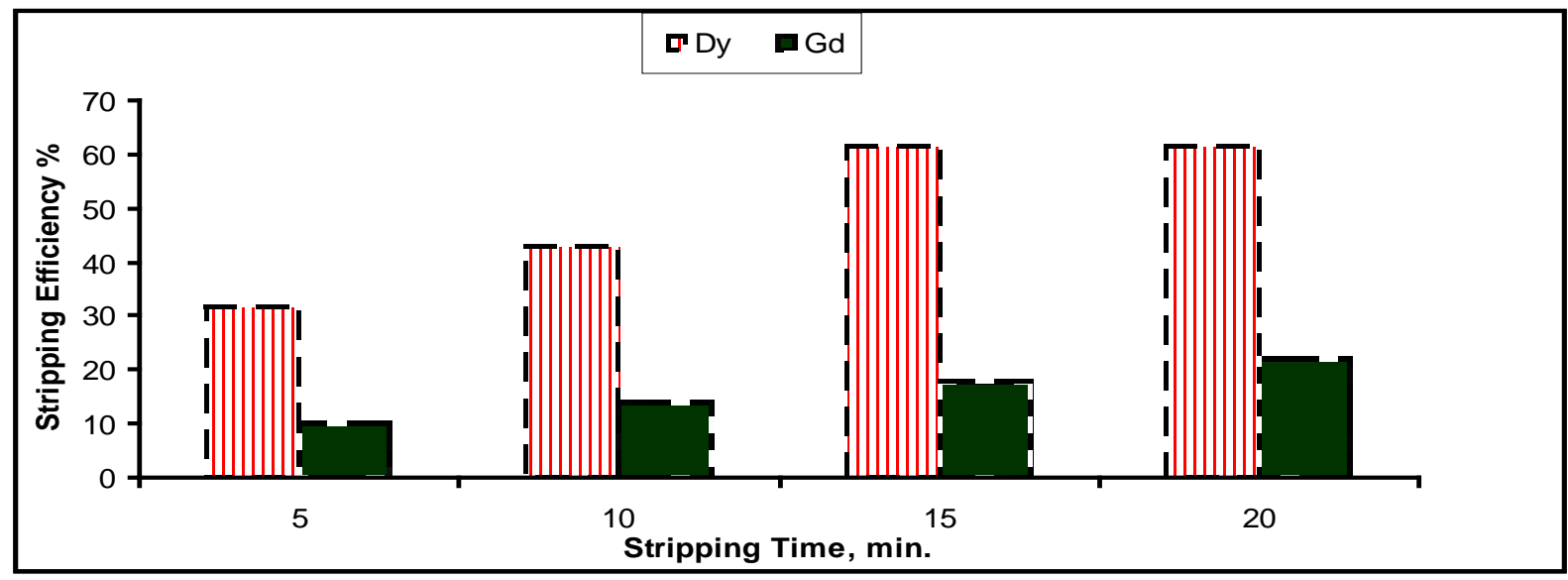

Fig.(10): Effect of time on the stripping of Dy and Gd 


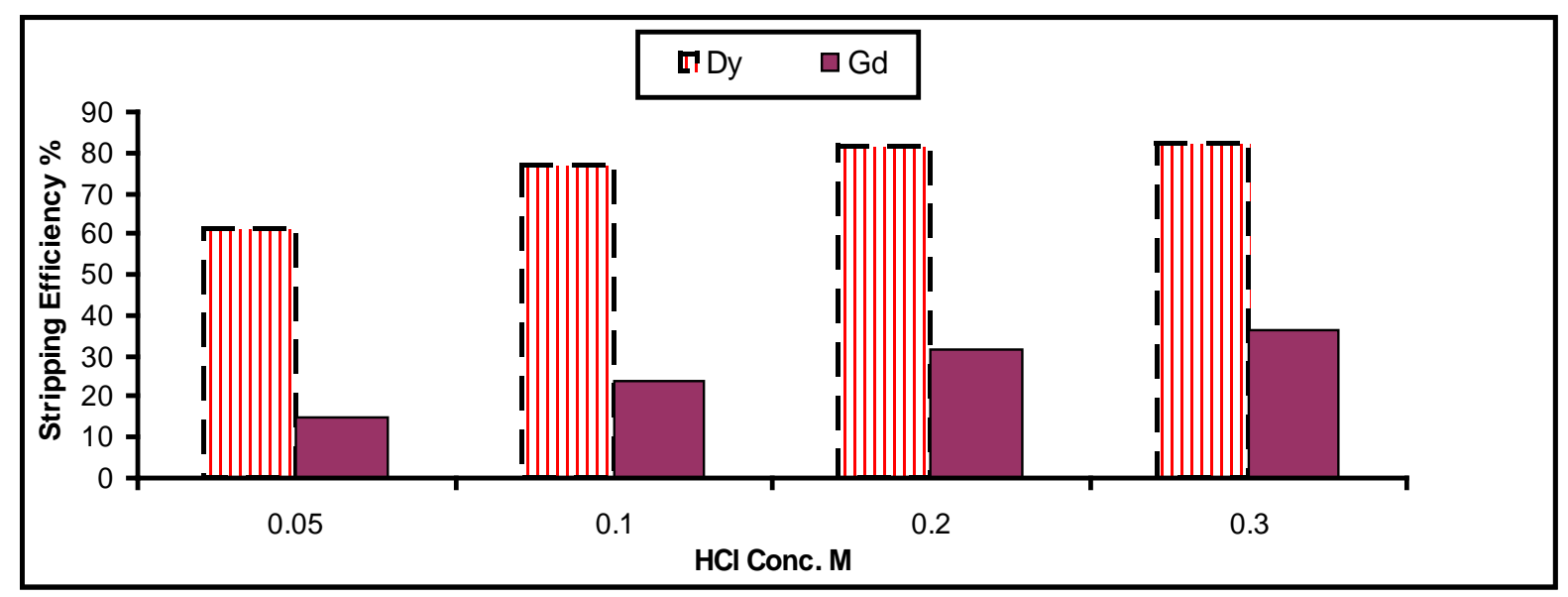

Fig.(11): Effect of HCl conc. on the stripping of rare earth elements (Dy and Gd)

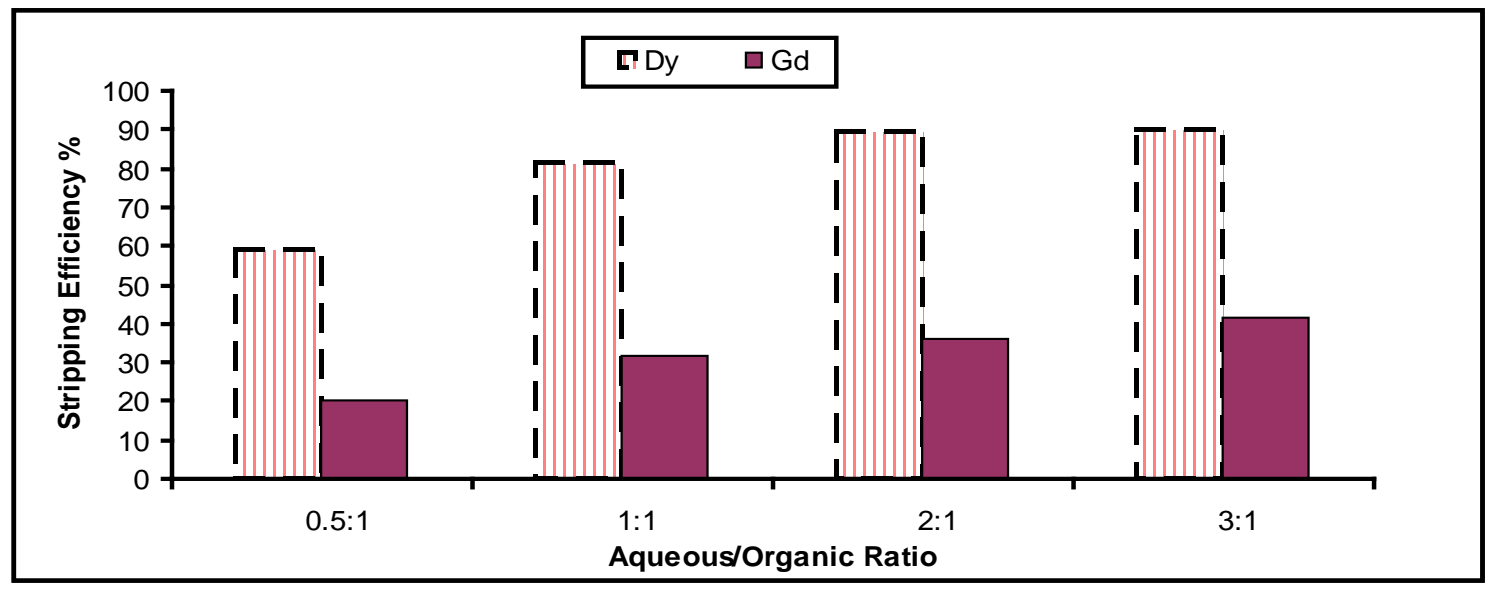

Fig.(12): Effect of aqueous/organic ratio on the stripping of Dy and Gd

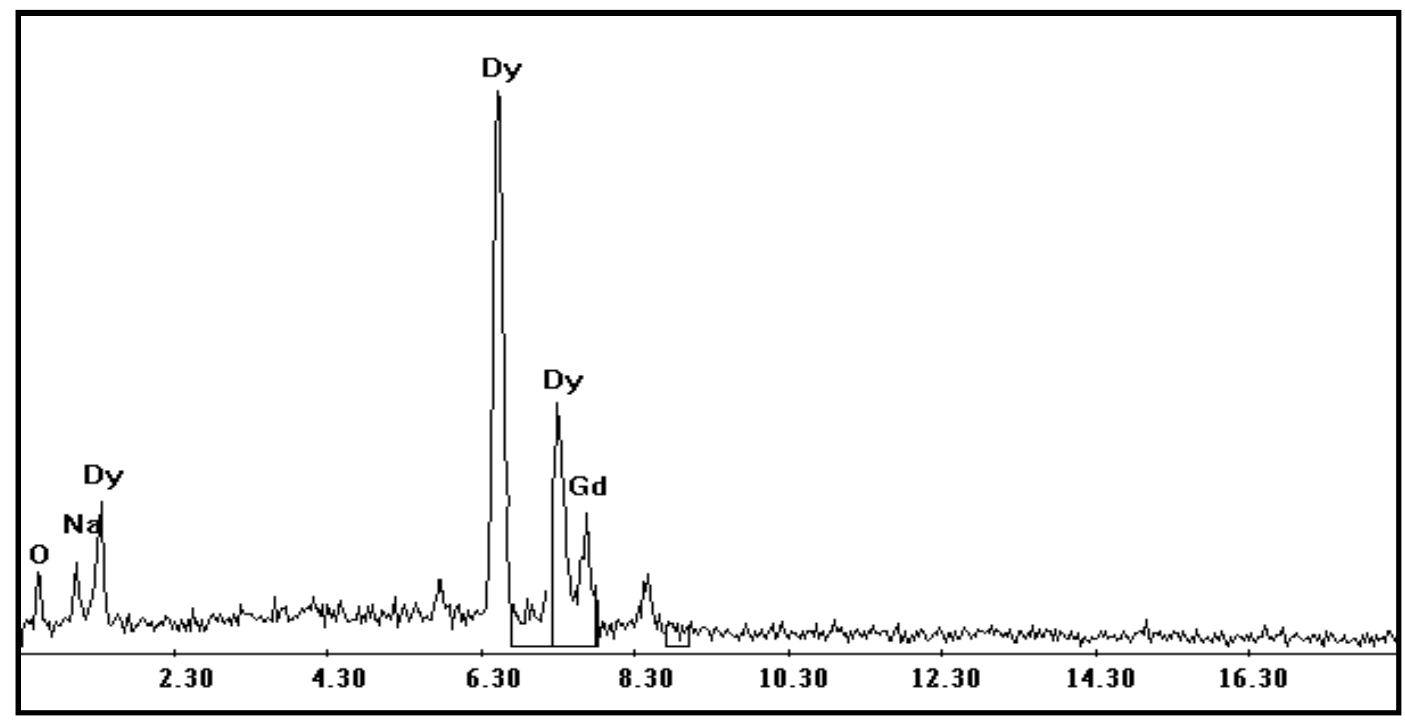

Fig.(13): Scan electron microscopy (SEM) for rare earth oxide product 


\section{Proposal Flow Sheet}

A successful extraction procedure of some heavy rare earths ( $\mathrm{Y}$ and Dy) from rare earths concentrate is obtained. The latter is prepared from digestion of xenotime bearing ferruginous sandstone by sulfuric acid followed by its precipitation using oxalic acid. This was possible through treatment of the concentrate by $\mathrm{Na} 2 \mathrm{CO} 3$ and extraction of dysprosium using cyanex 272 in kerosene using methanol as modifier (Fig. (14)). The corresponding relevant factors were studied and the conclusions can be summarized as follows:

1- The dissolution of rare earths concentrate using $\mathrm{HCl}$ then the treatment with $\mathrm{Na} 2 \mathrm{CO} 3$ was carried out. The optimum conditions are: 20 min. contact time using $5 \%$ of $\mathrm{Na} 2 \mathrm{CO} 3$ solution. The solubility efficiency \% reached the highest values of 88.3, 84.2, 64.6, 57.3, and 46.2 for Y, Dy, Er, Gd, and Yb respectively, while Ho not soluble as well as detected in the analysis. By the addition of (80 ml) H2O2, Dy,
Gd, \& Yb were precipitated while Y \& Er left behind in the filtrate which undergone precipitation by oxalic acid and fired to oxide.

2- Extraction of Dy from the obtained peroxy precipitate was performed using an equal phase ratio of $(0.4 \mathrm{M})$ cyanex 272 (with $0.3 \mathrm{M}$ methanol) in kerosene. The extraction efficiency was 87.3, 39.1, and 32.5\% for Dy, $\mathrm{Gd}$, and $\mathrm{Yb}$ respectively during $15 \mathrm{~min}$. and was reached 92.7, 54.7, and $42.5 \%$ respectively after 2nd extraction step. The stripping of 89.6 and $36.3 \%$ of Dy and Gd respectively was obtained using $0.2 \mathrm{M} \mathrm{HCl} \mathrm{(2:1}$ aqueous/organic phase ratio) at $15 \mathrm{~min}$. dysprosium is precipitated from the solution using oxalic acid.

3- Pure oxide of $\mathrm{Y}$ and Dy are obtained after calcination at $850^{\circ} \mathrm{C}$ for $2 \mathrm{~h}$. The latter oxides are subjected to ICP-MS and SEM analysis. The amount contains $0.25 \mathrm{~g}$ of the product gave a $\Sigma$ REO content of $97.9 \%$.

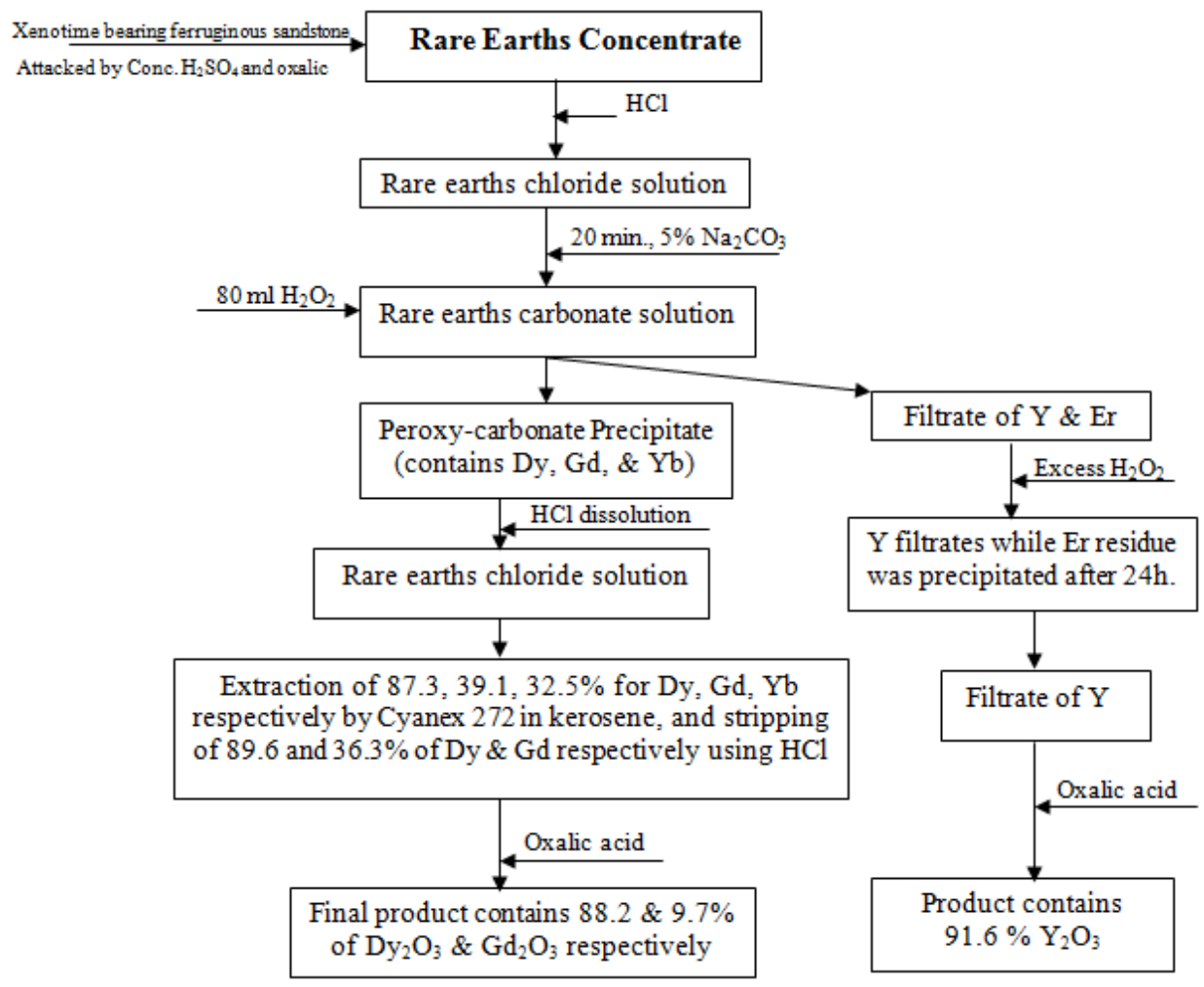

Fig. 14 proposal flow sheet for extraction of $Y$ and Dy from the xenotime bearing ferruginous sandstone of southwestern Sinai 


\section{Conclusion}

The recovery of $\mathrm{Y}$ \& Dy from rare earths concentrate, prepared by chemical processing of xenotime bearing ferruginous sandstone southwestern Sinai, was studied. Treatment and precipitation of the HREEs chloride with 5\% $\mathrm{Na} 2 \mathrm{CO} 3$ and $80 \mathrm{ml} \mathrm{H} 2 \mathrm{O} 2$ respectively were carried out. Yttrium was left behind in the filtrate, while the other REEs were precipitated. Extraction of $92.7 \%$ Dy was performed using Cyanex 272 modified in kerosene, while the stripping of $89.6 \%$ Dy was enhanced by $\mathrm{HCl}$. Y and Dy were precipitated by addition of oxalic acid from their corresponding solutions after being acidified with $\mathrm{HCl}$. Final product contains 88.2\% Dy2O3 and 9.7\% Gd2O3. The efficiency of Cyanex 272 for extraction of Dy was increased after the separation of Y.

Acknowledgements: The authors wish to thank the Egyptian Atomic Energy Authority for helping in the analysis of individual REEs by ICP-MS technique. The authors also thank the collaboration from the Egyptian Nuclear Materials Authority.

\section{References}

1- Xu, F., Zhang, L., Dong, X., Liu, Q., and Komuro, M.: Effect of DyF3 additions on the coercivity and grain boundary structure in sintered Nd-Fe-B magnets. Scripta Materialia, 64 (12), 1137-1140. DOI: 10.1016/j.scriptamat.2011.03.011(2011).

2- Seo, Y., and Morimoto, S.: Comparison of dysprosium security strategies in Japan for 2010 2030. In: Resources Policy, 39, 15-20. DOI:10.1016/j.resourpol.2013.10.007(2014).

3- Zepf, V.: Rare earth elements a new approach to the nexus of supply, demand and use: exemplified along the use of neodymium in permanent magnets, Springer, Berlin, 157p, ISBN-978-3-642-354571(2013).

4- Riano, S., and Binnemans, K.: Extraction and separation of neodymium and dysprosium from used NdFeB magnets: an application of ionic liquids in solvent extraction towards the recycling of magnets, Green Chemistry, 17, 2931-2942. DOI: 10.1039/c5gc00230c(2015).

5- Li, J., Zhang, C., Tang, Q., Hao, J., Zhang, Y., Su, Q., and Wang, S.: Photoluminescence and thermoluminescence properties of dysprosium doped zinc metaborate phosphors, J. Rare Earths, 26 (2), 203206. DOI: 10.1016/S1002-0721(08)60065-4(2008).

6- Xie, F., Zhang, T., Dreisinger, D., and Doyle, F.: A critical review on solvent extraction of rare earths from aqueous solutions, Minerals Engineering, 56, 10-28.DOI: 10.1016/ J.mineng.2013.10.021(2014).
7- Seredin, V.: A new method for primary evaluation of the outlook for rare earth element ores, Geology of Ore Deposits, 52 (5), 428-433. DOI: 10.1134/S1075701510050077(2010).

8- Musa, M., Azis, R., Osman, N., Hassan, J., and Zanhina, T.: Structural and magnetic properties of yttrium iron garnet (YIG) and yttrium aluminum iron garnet (YAlG) nanoferrite via sol-gel synthesis, Results in Physics 7, 1135-1142. DOI:10.1016/j.rinp.2017.02.038(2017).

9- Gupta, C., and Krishnamurthy, N.: Extractive metallurgy of rare earths, CRC Press, Bhabha Atomic Research Centre, Mumbai, India, 484p. ISBN 0-415-33340-7(2004).

10- Viyayalakshmi, R., Mishra, S., Singh, H., and Gupta, C.: Processing of xenotime concentrate by sulfuric acid digestion and selective thorium precipitation for separation of rare earths, Hydrometallurgy, 61(2), 75-80. DOI: 10.1016/S0304-386X0000159-6 (2001).

11- Gupta, B., Malik, P., and Deep, A.: Solvent extraction and separation of the tetravalent lanthanides and yttrium using cyanex 923, Solvent Extra. and Ion Exch., 21 (2), 239-258(2003).

DOI: 10.1081/SEI-120018948.

12- Reddy, M., Varma, R., Ramamohan, T., Sahu, S., Chakravortty, V.: Cyanex 923 as an extractant for trivalent lanthanides and yttrium, Solvent Extraction and Ion Exchange, 16 (3), 795-812. DOI: 10.1080/07366299808934553(1998).

13- Yoon, H., Kim, C., Chung, K., Kim, S., and Kumar, J.: Recovery process development for rare earths from permanent magnet scraps leach liquors, J. Braz. Chem. Soc., 26 (6), 1143-1151, São Paulo. DOI: 10.5935/0103-5053.20150077(2015).

14- Wang, Y., Liao, W., and Li, D.: A solvent extraction process with mixture of CA12 and Cyanex272 for the preparation of high purity yttrium oxide from rare earth ores, Separation and Purification Technology, 82, 197-201. DOI:10.1016/j.seppur.2011.09.018(2011).

15- Jorjani, E. and Shahbazi, M.: The production of rare earth elements group via tributyl phosphate extraction and precipitation stripping using oxalic acid. Arab. J. Chem., 9, 1532-1539. DOI: 10.1016/j.arabjc.2012.04.002(2016).

16- Mohammadi, M., Forsberg, K., Kloo, L., Cruz, J. M., Rasmuson, A.: Separation of $\mathrm{Nd}(\mathrm{III})$, Dy(III) and Y(III) by solvent extraction using D2EHPA and EHEHPA, Hydrometallurgy, 156, 215-224. DOI: 10.1016/j.hydromet.2015.05.004(2015).

17- Vasconcellos, M., Rocha, S., Pedreira, W., Queiroz, C., and Abrao, A.: Enrichment of Y from rare earth concentrate by ammonium carbonate leaching and peroxide precipitation, J. Alloys \& compounds, 418,200-203.

DOI:10.1016/j.jallcom.2005.10.076(2006). 
Recovery of Yttrium and Dysprosium.....

18- El Hady, S.: Studies on extraction of uranium from sandstone adediya formation, Wadi El Sahu, southwestern Sinai, Egypt. Ph.D. Thesis, Faculty of Science, Zagazig University, Egypt, 187p (2013).

19- Wang, Z., Yan, X., Wang, Z., Zhang, Z., and Liu, L.: Flow injection on-line solid phase extraction coupled with inductively coupled plasma mass spectrometry for determination of (Ultra) trace rare earth elements in environmental materials using maleic acid grafted poly-tetra-fluoro-ethylene fibers as sorbent, J. Am. Soc. Mass Spectrometry, 17 (9), 1258-1264.

DOI:10.1016/j.jasms.2006.05.011(2006).

20- Buchalova, M., Komorova, L., Galova, M., and Lengyel, J.: Separation of rare earth elements I. Extraction of Sm, Pr, Nd with tributyl phosphate from nitrate solutions, Chemical Papers, 44 (4), 557-565(1990).

21- Thurman, E., and Mills, M.: Solid Phase Extraction; Principles and Practice, John Wiley and Sons, Inc., New York, 988P. DOI: 10.1002/(SICI)1097-0231(19980731)12:14(1997).
22- Vasconcellos, M., Queiroz, C., Abrao, A.: Sequential separation of the yttrium-heavy rare earths by fractional hydroxide precipitation, J. Alloys \& Compounds, 374, 405-407. DOI:10.1016/j.jallcom.2003.11.038(2004).

23- Gupta, C., and Krishnamurthy, N.: Extractive metallurgy of rare earths, International Materials Reviews, (37) 5, 204-216(1992).

24- Gupta, C., and Krishnamurthy, N.: Extractive metallurgy of rare earths, 1st Ed, CRC Press, New York, NY, USA, 222 p(2005).

25- Ramachandran, V., Paroli, R., Beaudoin, J., Delgado, A. : Handbook of thermal analysis of construction materials, Noyes Publications, New York, USA, 524p(2002).

26- Preston, J., Cole, P., Craig, W., and Feather, A.: The recovery of rare earth oxides from a phosphoric acid by-product. Part 1: Leaching of rare earth values and recovery of a mixed rare earth oxide by solvent extraction, Hydrometallurgy, (41), 1-19. DOI: 10.1016/0304-386X(95)00051H(1996). 